\title{
TWO NEW SPECIES OF BISETOCREAGRIS ĆURČIĆ, 1983 (PSEUDOSCORPIONES: NEOBISIIDAE) FROM CHINA
}

\author{
Xiangbo Guo and Feng Zhang \\ The Key Laboratory of Invertebrate Systematics and Application, College of Life Sciences \\ Hebei University, Baoding, Hebei 071002, P. R. China; E-mail: dudu06042001@163.com
}

Two new Bisetocreagris species belonging to the family Neobisiidae are described from China: Bisetocreagris yangae sp. $\mathbf{n}$. from Anhui Province and Bisetocreagris parva sp. $\mathbf{n}$. from Zhejiang Province. Detailed diagnoses, descriptions and illustrations of the two new species are presented.

Key words: taxonomy, pseudoscorpion, Bisetocreagris, new species.

\section{INTRODUCTION}

The pseudoscorpion family Neobisiidae Chamberlin, 1930 is primarily distributed in the northern temperate regions of the world. Thirty-two genera belonging to two subfamilies (Microcreagrinae Balzan, 1892 and Neobisiinae Chamberlin, 1930) have been described worldwide, and five of these have been recorded from China: Microcreagris Balzan, 1892, Stenohya Beier, 1967 and Bisetocreagris Ćurčić, 1983 in Microcreagrinae; Microbisium Chamberlin, 1930 and Parobisium Beier, 1930 in Neobisiinae (Harvey 2013).

The genus Bisetocreagris was erected by ĆURčıć (1983) with the type species B. annamensis Beier, 1951, and consisted of 7 species. Pedalocreagris Ćurčić, 1985 (Judson 1993) and Chinacreagris Ćurčić, 1983 (HARvey 1999) were synonymized with Bisetocreagris. Currently, the genus Bisetocreagris includes 26 species and subspecies (Harvey 2013), including 11 species reported from China: B. kaznakovi kaznakovi (Redikorzev, 1918), B. lampra (Chamberlin, 1930), B. orientalis (Chamberlin, 1930), B. silvestrii (Chamberlin, 1930), B. ussuriensis (Redikorzev, 1934), B. indochinensis (Redikorzev, 1938), B. annamensis (Beier, 1951), B. kwantungensis (Beier, 1967), B. nankingensis (Ćurčić, 1983), B. thailandica Schawaller, 1994 and B. cheni Jia, Zhao \& Zhu, 2010 (Zнно et al. 2011).

During examination of material deposited in the Museum of Hebei University (MHBU), two Bisetocreagris species new to science were found and are described hereby as B.yangae sp. n. and B. parva sp. n. 


\section{MATERIAL AND METHODS}

All specimens were examined and illustrated using a Leica 205A stereomicroscope with a drawing tube, which was also used for the measurements. Detailed examination was carried out with an Olympus BX53 general optical microscope. Temporary slide mounts were prepared in glycerol. All measurements are given in $\mathrm{mm}$. The specimens are deposited in the Museum of Hebei University (MHBU), Baoding, China, preserved in $85 \%$ alcohol.

Terminology of trichobothria follows Chamberlin (1931) and Harvey (1992). The term "rallum" (for flagellum) is adopted following Judson (2007). The following abbreviations are used in the text for the trichobothria: $b=$ basal, $s b=$ sub-basal, st = sub-terminal, $\mathrm{t}=$ terminal, $\mathrm{ib}=$ interior basal, is $\mathrm{b}=$ interior sub-basal, ist $=$ interior sub-terminal, it $=$ interior terminal, eb = exterior basal, esb = exterior sub-basal, est = exterior sub-terminal, et = exterior terminal.

\section{TAXONOMY}

\section{Bisetocreagris yangae $\mathrm{sp} . \mathrm{n}$. (Figs 1-3)}

Type material - Holotype male (Ps.-MHBU-AH13102301), China: Anhui Province,

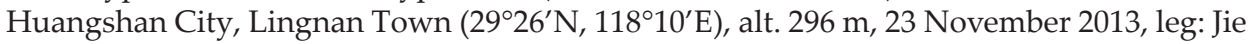
Yang. Paratypes: three males and seven females (Ps.-MHBU - AH13102302-11), same data as for holotype.

Etymology - The specific name is a patronym in honour of Ms Jie Yang, who collected the specimens.

Diagnosis - Rallum consists of 8 blades; pedipalpal femur, patella and chela smooth, femur 2.60-2.78, patella 1.57-1.65, chela (without pedicel) 2.182.42 times longer than broad, movable finger $0.72-0.82$ times longer than hand (without pedicel); sternite III with 3-4 setae on the anterior margin, and 6-7 setae on the internal parts of the genitalia in male.

Description - Male (Fig. 1a) - Colour mostly brown, pedipalps darker, legs yellow. Setae of body straight and acicular.

Carapace (Figs 2a, 3b) - Smooth, 0.97-1.06 times longer than broad, with a total of 26-29 setae, including 4 on the anterior margin and 8-9 on the posterior margin; paired lyrifissures near the eyes and posterior margin; epistome small, triangular; 4 eyes, anterior pair with lens, posterior pair with weak lens.

Chelicera (Figs 2b, 3c) - Hand with 7 setae, movable finger with 1 seta; fixed finger with 6-9 teeth; movable finger with 7-9 teeth; serrula exterior with 35-39 lamellae; serrula interior with 20-22 lamellae. Galea (Fig. 2c) with two terminal branches. Rallum (Fig. 2e) consists of 8 blades, all with anteriorly-directed spinules, basalmost blade the shortest and distalmost blade widened at base.

Pedipalps (Figs 2f,g, 3a,d) - Apex of pedipalpal coxa rounded, with 4 setae. Femur, patella and chela smooth; chelal fingers shorter than hand. Trochanter 1.28-1.41, femur 2.60-2.78, patella 1.57-1.65, chela (with pedicel) 2.29-2.61, chela (without pedicel) 2.18-2.42 
times longer than broad, movable finger 0.72-0.82 times longer than hand (without pedicel). Fixed chelal finger with 8 and movable finger with 4 trichobothria: $e b$ and $e s b$ on lateral margin of hand; $i b$, is $b$ and ist in basal half, et and it in distal half, est almost in the middle of fixed finger; $t$ and st near the middle of movable finger, $s b$ and $b$ on basal half. Venom apparatus present only in fixed chelal finger, venom duct very short. Chelal teeth rounded and contiguous, fixed finger with 50-55 and movable finger with 64-67 teeth.

Abdomen - Pleural membrane granulated. Tergites and sternites with uniseriate setation, tergal chaetotaxy (I-X): 11-13: 13: 14: 15-16: 15-16: 15: 15: 15-16: 14: 11-12, sternal chaetotaxy (IV-X): 8-12: 15-17: 17-18: 17-20: 17-18: 15-17: 13; stigmata with 5-7 setae on anterior margin; anal cone with 2 dorsal and 2 ventral setae. Male genital area (Figs $2 \mathrm{~h}$, 3e): sternite II with 20-25 scattered setae; sternite III with 3-4 setae on the anterior margin, anteromedian groove absent, followed by 18 intermediary and posterior setae; there are 6-7 setae on the internal parts of the genitalia.

Legs - Leg I (Figs 2j, 3g) and leg IV (Figs 2k, 3h) typical. Tibia IV with one sub-medial tactile seta (TS=0.41-0.44), basitarsus IV with a basal tactile seta (TS=0.17-0.21), telotarsus IV with one sub-medial tactile seta (TS=0.43-0.49). Subterminal tarsal seta bifurcate; arolium not divided, shorter than the slender and simple claws.

Female (Fig. 1b) - as in holotype except where noted.
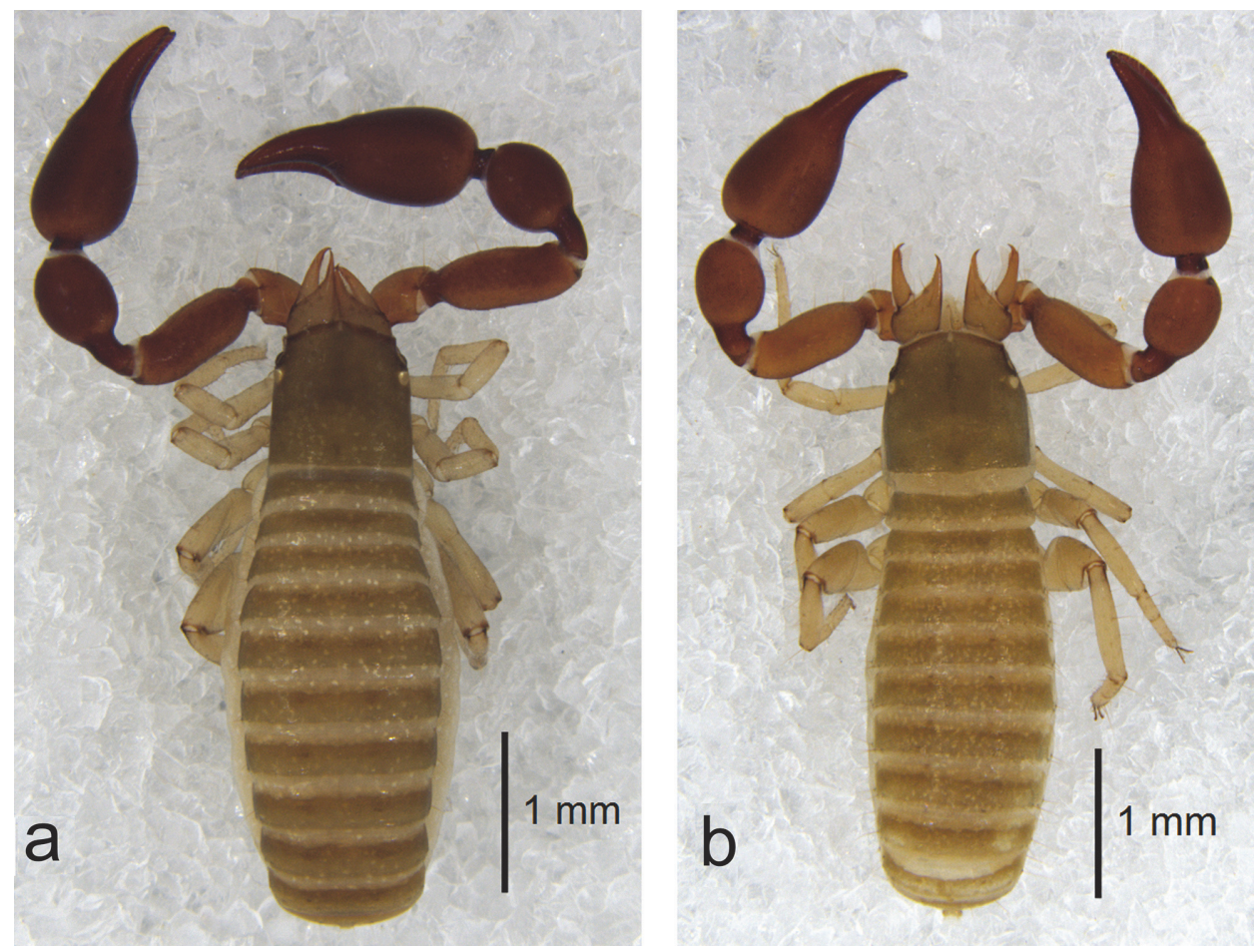

Fig. 1. Bisetocreagris yangae sp. n.: a = holotype male, habitus, dorsal view, $\mathrm{b}=$ paratype female, habitus, dorsal view 

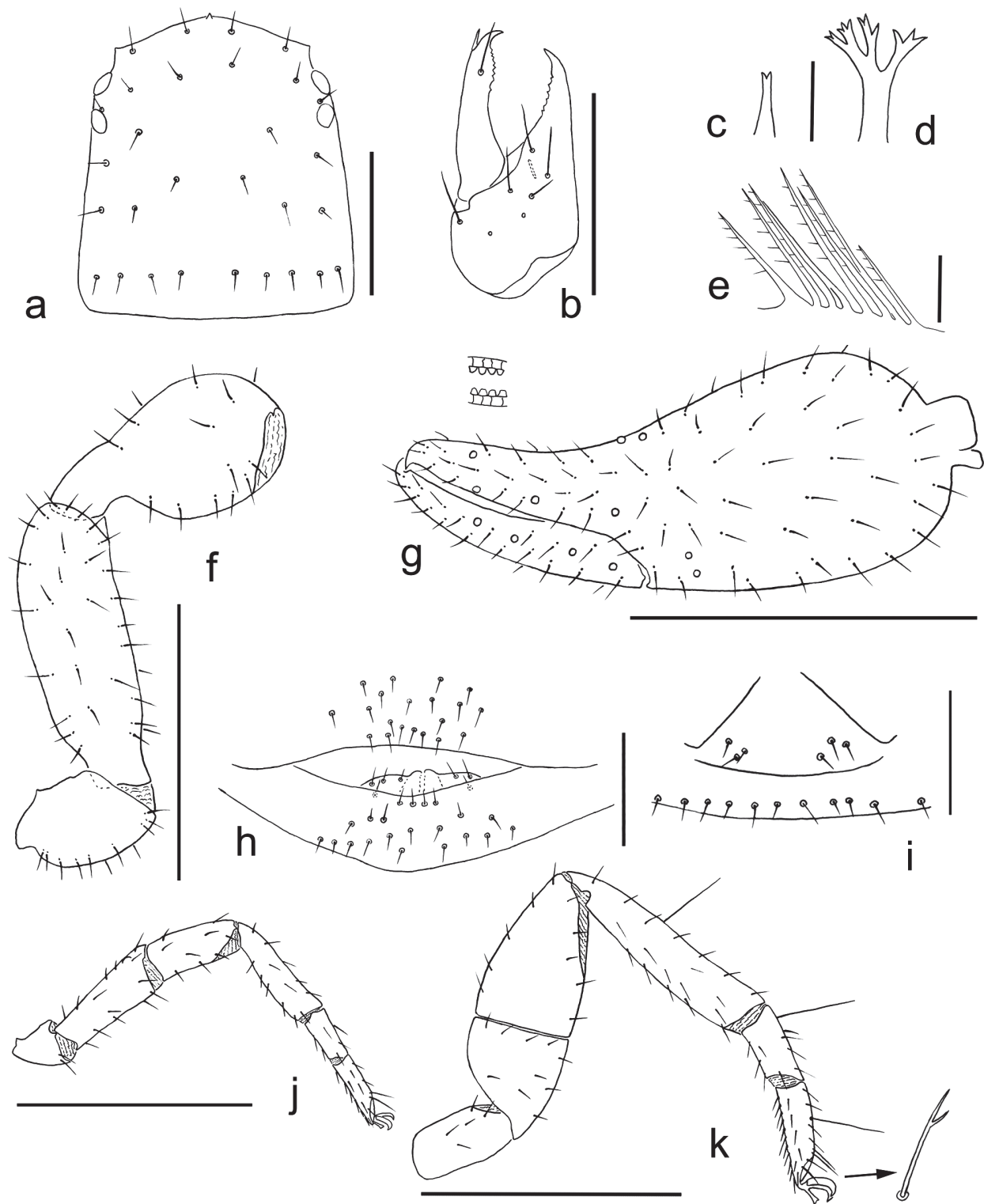
Chelicera - Fixed finger with 6-7 teeth; movable finger with 8-10 teeth; serrula exterior with 39-42 lamellae; serrula interior with 26-28 lamellae. Galea well developed, structure as shown in Figure 2d.

Pedipalps - Trochanter 1.34, femur 2.33-2.50, patella 1.58-1.69, chela (with pedicel) 2.37-2.38, chela (without pedicel) 2.21-2.22 times longer than broad, movable finger 0.770.82 times longer than hand (without pedicel). Chelal teeth rounded and contiguous, fixed finger with 39-43 and movable finger with 47-52 teeth.

Abdomen - Tergites and sternites with uniseriate setation, tergal chaetotaxy (I-X): 11-12: 12-15: 13-14: 14-15: 14-15: 15-17: 12-17: 13-16: 12-15: 9-11, sternal chaetotaxy (IVX): 10-11: 14-17: 17: 17-19: 16-17: 17: 13-14. Female genital area (Figs 2i, 3f): sternite II with 3-4 setae on each side; sternite III with a row of 12-14 setae on the posterior margin.

Measurements (length/breadth or depth in $\mathrm{mm}$, ratios in parentheses) - Male. Body length 3.78-4.35. Carapace $0.94-0.95 \times 0.90-0.97(0.97-1.06)$. Chelicera $0.48-0.62 \times 0.28-0.33$ (1.71-1.88), movable finger length $0.32-0.40$. Pedipalpal trochanter $0.41 \times 0.29-0.32(1.28-$ 1.41), femur $0.91-1.03 \times 0.35-0.37$ (2.60-2.78), patella $0.76-0.80 \times 0.46-0.51$ (1.57-1.65), chela (with pedicel) $1.42-1.67 \times 0.62-0.64$ (2.29-2.61), chela (without pedicel) $1.35-1.55 \times 0.62-0.64$ (2.18-2.42), hand length (without pedicel) $0.81-0.88$, movable finger length $0.58-0.72(0.72-$ $0.82 \times$ hand). Leg I: trochanter $0.18-0.19 \times 0.17-0.19(0.95-1.12)$, femur $0.44-0.51 \times 0.17-0.20$ (2.55-2.59), patella $0.34-0.57 \times 0.17-0.18(2.00-3.17)$, tibia $0.44-0.48 \times 0.11-0.13(3.69-4.00)$, basitarsus $0.17-0.20 \times 0.09-0.10(1.89-2.00)$, telotarsus $0.28-0.29 \times 0.09(3.11-3.22)$. Leg IV: trochanter $0.30-0.41 \times 0.22-0.23(1.30-1.86)$, femur + patella $0.93-0.96 \times 0.36-0.37(2.58-2.59)$, tibia $0.80-0.81 \times 0.18-0.19(4.26-4.44)$, basitarsus $0.24-0.30 \times 0.13-0.14(1.85-2.14)$, telotarsus $0.35 \times 0.12(2.92)$.

Female. Body length 3.93-4.45. Carapace 0.99-1.08×1.00-1.04 (0.99-1.04). Chelicera: $0.56-0.65 \times 0.35-0.38(1.60-1.71)$, movable finger length $0.39-0.42$. Pedipalpal trochanter $0.43-0.47 \times 0.32-0.35(1.34)$, femur $0.90-0.98 \times 0.36-0.42(2.33-2.50)$, patella $0.81-0.84 \times 0.48-$ 0.53 (1.58-1.69), chela (with pedicel) $1.59-1.71 \times 0.67-0.72(2.37-2.38)$, chela (without pedicel) $1.48-1.60 \times 0.67-0.72(2.21-2.22)$, hand length (without pedicel) $0.88-0.96$, movable finger length $0.72-0.74(0.72-0.82 \times$ hand). Leg I: trochanter $0.21-0.23 \times 0.18(1.17-1.28)$, femur $0.41-$ $0.45 \times 0.16-0.17(2.56-2.65)$, patella $0.25-0.31 \times 0.16-0.17(1.47-1.94)$, tibia $0.39-0.44 \times 0.12-0.13$ (3.25-3.38), basitarsus $0.19-0.21 \times 0.09-0.10(2.10-2.11)$, telotarsus $0.28-0.29 \times 0.08-0.09(3.11-$ 3.63). Leg IV: trochanter $0.31-0.33 \times 0.24-0.26(1.27-1.29)$, femur + patella $0.91-0.97 \times 0.36-$ $0.38(2.53-2.55)$, tibia $0.66-0.81 \times 0.18-0.19(3.67-4.26)$, basitarsus $0.29-0.31 \times 0.13(2.23-2.38)$, telotarsus $0.37-0.39 \times 0.12-0.13(3.00-3.08)$.

Distribution - China (Anhui).

Remarks - This new species has 3-4 setae on the anterior margin of sternite III in the male instead of 2, but its trichobothrial pattern and rallum structure conform to the characteristics of the genus Bisetocreagris. Schawaller, 1985 noticed this difference first in B. tenuis Redikorzev, 1934. DashDamirov and Schawaller, 1992 also noted this in B. gracilis Redikorzev, 1934, B. kaznakovi Redikorzev, 1918 and B. turkestanica Beier, 1929. Dashdamirov and SchAWALLER, 1992 suggested that species separation is based on the distinction of proportions, granulations, dentations and trichobothriotaxy of the pedipalps (not the structure of the genital area) in the genus Bisetocreagris. 

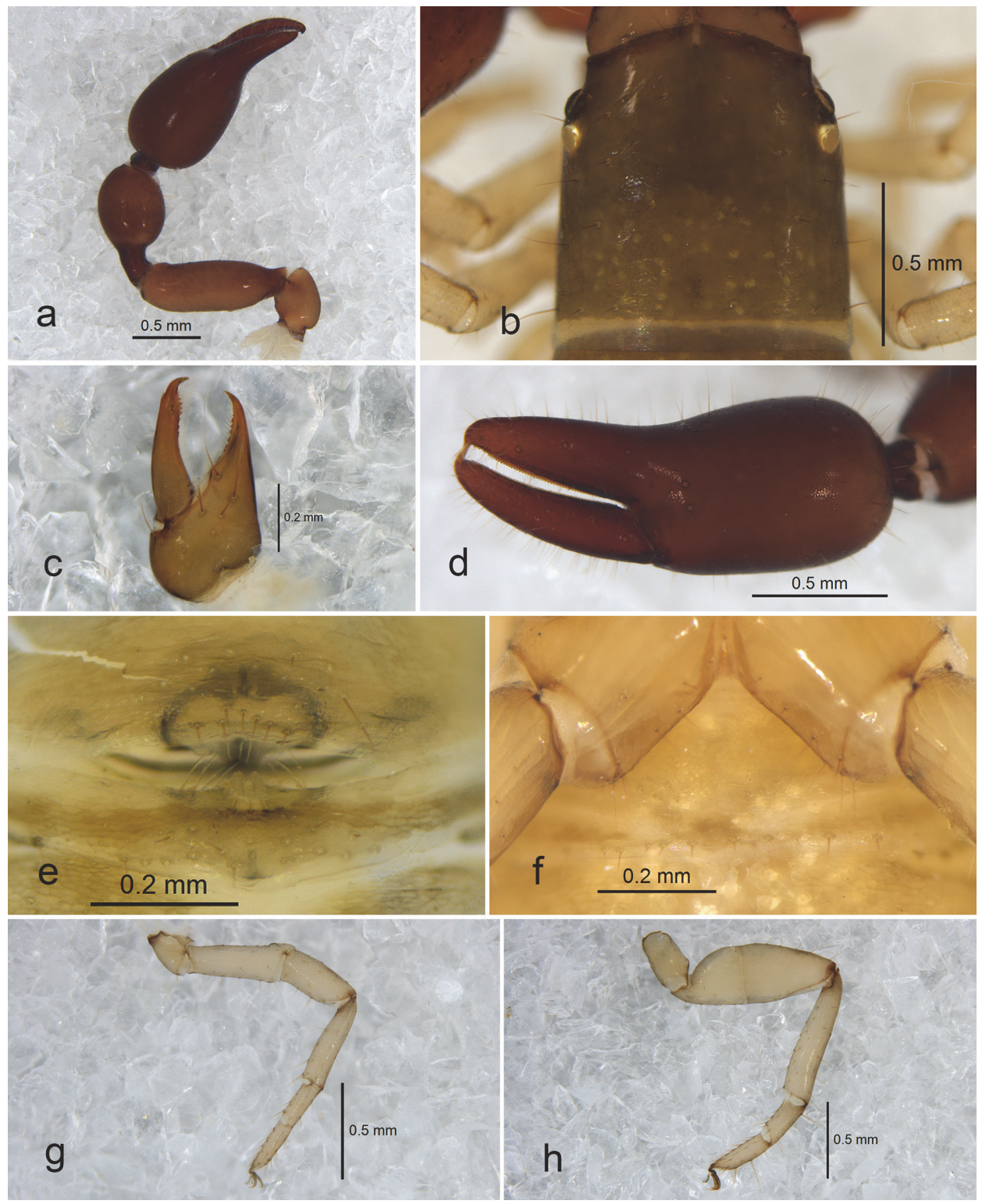

Fig. 3. Bisetocreagris yangae sp. n., holotype male (Figs a-e, g, h), paratype female (Fig. f): a = left pedipalp, dorsal view, $\mathrm{b}=$ carapace, dorsal view, $\mathrm{c}=$ left chelicera, dorsal view, $\mathrm{d}=$ left chela, lateral view, $\mathrm{e}=$ genital area of male, $\mathrm{f}=$ genital area of female, $\mathrm{g}=$ right leg $\mathrm{I}$, lateral view, $\mathrm{h}=$ right leg IV, lateral view 
The chelal fingers of $B$. yangae are shorter than the hand; this also occurs in B. japonica (Ellingsen, 1907), B. brevidigitata (Chamberlin, 1930) and B. silvestrii. $B$. yangae can be distinguished from these species by its smooth pedipalps, pedipalpal femur and chelal hand with distinct granulations in B. japonica, and the anterior face of pedipalpal femur slightly granulate in B. brevidigitata and B. silvestrii (Harvey 1999). Additionally, B. yangae differs from B. brevidigitata and $B$. silvestrii by the following characters: rallum with 8 blades (rallum with 7 blades in B. brevidigitata female), shorter chelal fingers (movable finger $0.92 \mathrm{vs}$ 0.72-0.82 times longer than hand in B. silvestrii) and movable chelal finger with 64-67 teeth (about 78 teeth in B. silvestrii).

\section{Bisetocreagris parva sp. $n$.}

(Figs 4-6)

Type material - Holotype male (Ps.-MHBU-ZJ13102701), China: Zhejiang Province, Hangzhou City, Tonglu County, Phoenix Cemetery $\left(29^{\circ} 49^{\prime} \mathrm{N}, 119^{\circ} 41^{\prime} \mathrm{E}\right)$, alt. $40 \mathrm{~m}$, 27 October 2013, leg: Zhizhong Gao. Paratypes: two males and four females (Ps.-MHBU - ZJ13102702-07), same data as for holotype.

Etymology - The specific name is derived from the Latin adjective "parvus", meaning small, referring to the body size of the new species.

Diagnosis - Small species, length of pedipalpal femur at most $0.39 \mathrm{~mm}$; rallum with 7 blades; pedipalpal femur, patella and chela with granulations on medial face, femur 2.50, patella 2.06-2.20, chela (without pedicel) 3.05-3.18 times longer than broad, movable finger 1.48-1.57 times longer than hand (without pedicel).

Description - Male (Fig. 4a) - Colour mostly pale yellow, pedipalps, carapace and chelicerae reddish yellow. Setae of body straight and acicular.

Carapace (Figs 5a, 6a) - Smooth, 1.22-1.24 times longer than broad, with a total of 24 setae, including 4 on the anterior margin and 6 on the posterior margin; epistome small, triangular; 4 eyespots, with weak lens.

Chelicera (Figs 5b, 6d) - Hand with 7 setae, movable finger with 1 seta; fixed finger with 9-11 teeth; movable finger with 7 teeth; serrula exterior with 32-35 lamellae; serrula interior with 28-30 lamellae. Galea (Fig. 5c) small and acuminate, without bifurcation. Rallum (Fig. 5e) with 7 blades, all with anteriorly-directed spinules, basalmost blade the shortest and distalmost blade widened at base.

Pedipalps (Figs 5f,g, 6b,c) - Apex of pedipalpal coxa rounded, with 3 setae. Pedipalpal femur and patella with granulations on medial face, femur sturdy, chela with granulations on medial and lateral face. Trochanter 1.73-1.91, femur 2.50, patella 2.06-2.20, chela (with pedicel) 3.26-3.47, chela (without pedicel) 3.05-3.18 times longer than broad, movable finger 1.48-1.57 times longer than hand (without pedicel). Fixed chelal finger with 8 and movable finger with 4 trichobothria: $e b$ and $e s b$ on lateral margin of hand, and $e s b$ slightly above $e b ; i b$, is $b$ and ist in basal half, est, et and it in distal half of fixed finger, and et 
more distal than it; $t$ and st near the middle of movable finger, sb and $b$ in basal half. Venom apparatus present only in fixed chelal finger, venom duct very short. Chelal teeth rounded and contiguous, fixed finger with 49-52 and movable finger with 43-47 teeth.

Abdomen - Pleural membrane granulated. Tergites and sternites with uniseriate setation, tergal chaetotaxy (I-X): 9-10: 11: 11: 11-12: 11-12: 11: 11-12: 12: 9-11: 10-11, sternal chaetotaxy (IV-X): 9-10: 13-14: 13-14: 13-15: 12-14: 11-13: 11-12; stigmata with 2 small setae on anterior margin, anal cone with 2 dorsal and 2 ventral setae. Male genital area (Figs 5h, 6e): sternite II with a median and posterior group of 13-14 setae; sternite III with an anteromedian bisetous groove, followed by 10-14 median and posterior setae.

Legs - Leg I (Figs 5j, 6g) and leg IV (Figs 5k, 6h) typical. Tibia IV with one middle tactile seta (TS=0.48-0.50), basitarsus IV with one tactile seta in basal half (TS=0.22), telotarsus IV with one sub-medial tactile seta $(\mathrm{TS}=0.40)$. Subterminal tarsal seta bifurcate; arolium not divided, shorter than the slender and simple claws.

Female (Fig. 4b) - as in holotype except where noted.

Chelicera - Fixed finger with 8-9 teeth; movable finger with 7-8 teeth; serrula exterior with 34-37 lamellae; serrula interior with 32-35 lamellae. Galea (Fig. 5d) divided into two main branches, each tine distally bifurcate.

Pedipalps - Trochanter 1.50-1.67, femur 2.40-2.44, patella 2.06-2.12, chela (with pedicel) 3.09-3.20, chela (without pedicel) 2.82-2.95 times longer than broad, movable finger 1.20-1.29 times longer than hand (without pedicel). Chelal teeth rounded and contiguous, fixed chelal finger with 49-54 and movable finger with 41-46 teeth.
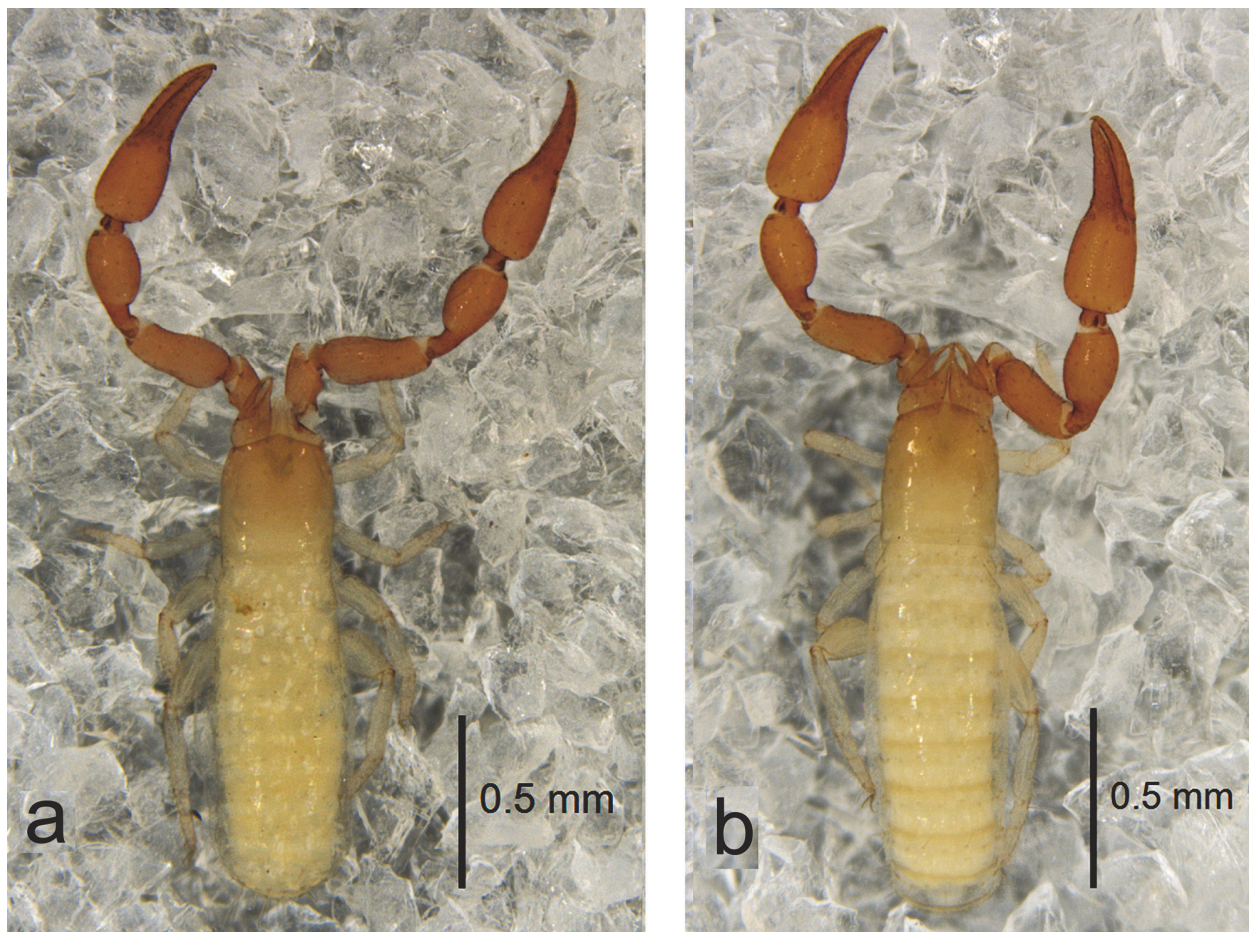

Fig. 4. Bisetocreagris parva sp. n.: a = holotype male, habitus, dorsal view, $\mathrm{b}=$ paratype female, habitus, dorsal view 


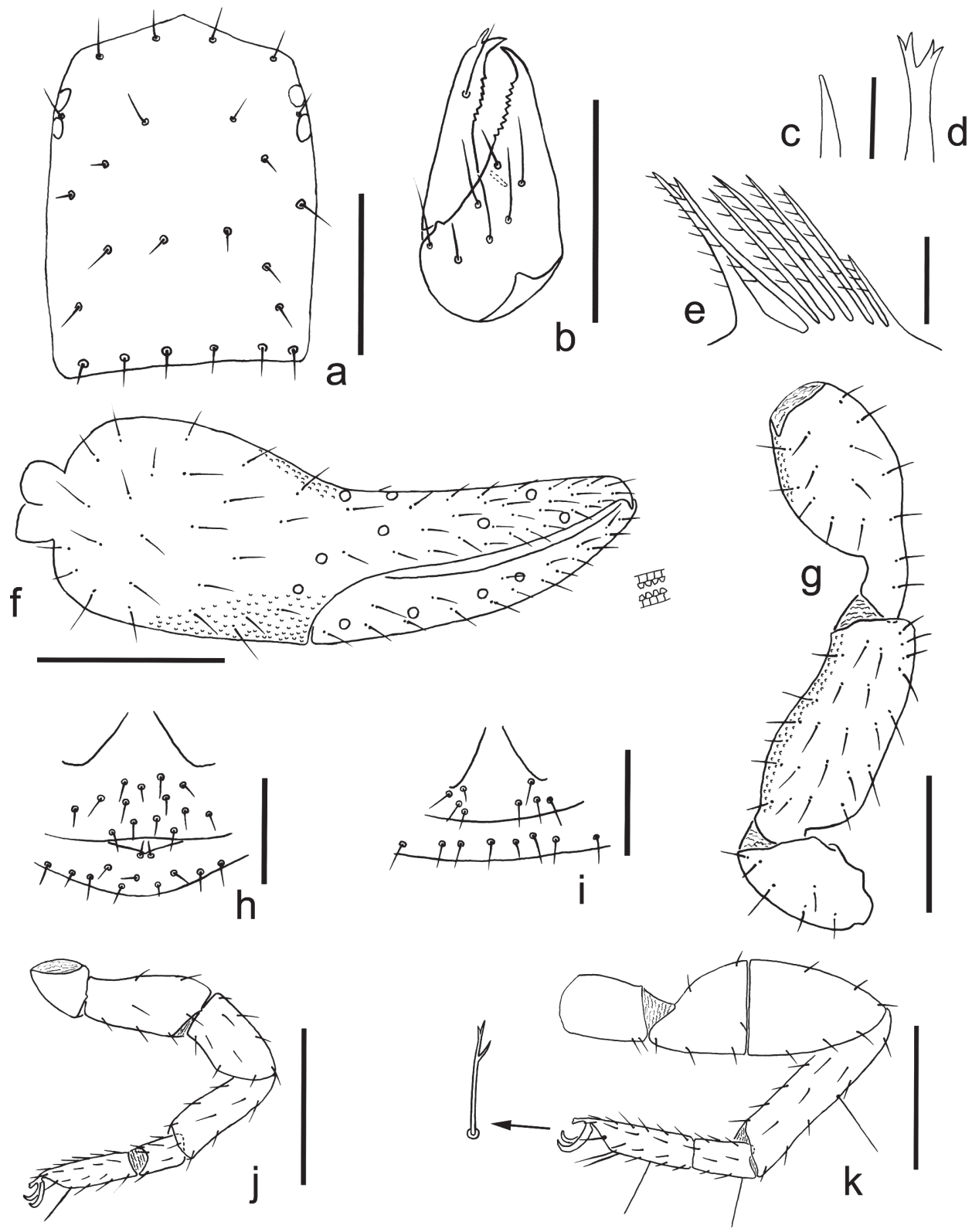

Fig. 5. Bisetocreagris parva sp. n., holotype male (Figs a-c, e-h, j-k), paratype female (Figs d, i): $a=$ carapace, dorsal view, $b=$ left chelicera, dorsal view, $c$ = galea of male, $d$ = galea of female, $\mathrm{e}=$ rallum, $\mathrm{f}=$ right chela, lateral view, showing trichobothriotaxy and teeth, $\mathrm{g}=$ right pedipalp, dorsal view (trochanter, femur and patella), $\mathrm{h}=$ genital area of male, $\mathrm{i}=$ genital area of female, $\mathrm{j}=$ right leg $\mathrm{I}$, lateral view, $\mathrm{k}=$ right leg IV, lateral view. Scale bars: $0.02 \mathrm{~mm}$ (c-e); $0.10 \mathrm{~mm}(\mathrm{~h}, \mathrm{i}) ; 0.20 \mathrm{~mm}(\mathrm{a}, \mathrm{b}, \mathrm{f}, \mathrm{g}, \mathrm{j}, \mathrm{k})$ 
Abdomen - Tergites and sternites with uniseriate setation, tergal chaetotaxy (I-X): 9-11: 10-11: 10-11: 11-12: 11: 11-12: 11-12: 11: 11: 10-11, sternal chaetotaxy (IV-X): 8-9: 11-12: 13-14: 13: 13-14: 12-13: 11. Female genital area (Figs 5i, 6f): sternite II with 4-5 setae on each side; sternite III with a row of 7-8 setae on the posterior margin.

Measurements (length/breadth or depth in mm) - Male. Body length 1.53-1.61. Carapace $0.39-0.42 \times 0.32-0.34(1.22-1.24)$. Chelicera $0.22-0.23 \times 0.12(1.83-1.91)$, movable finger

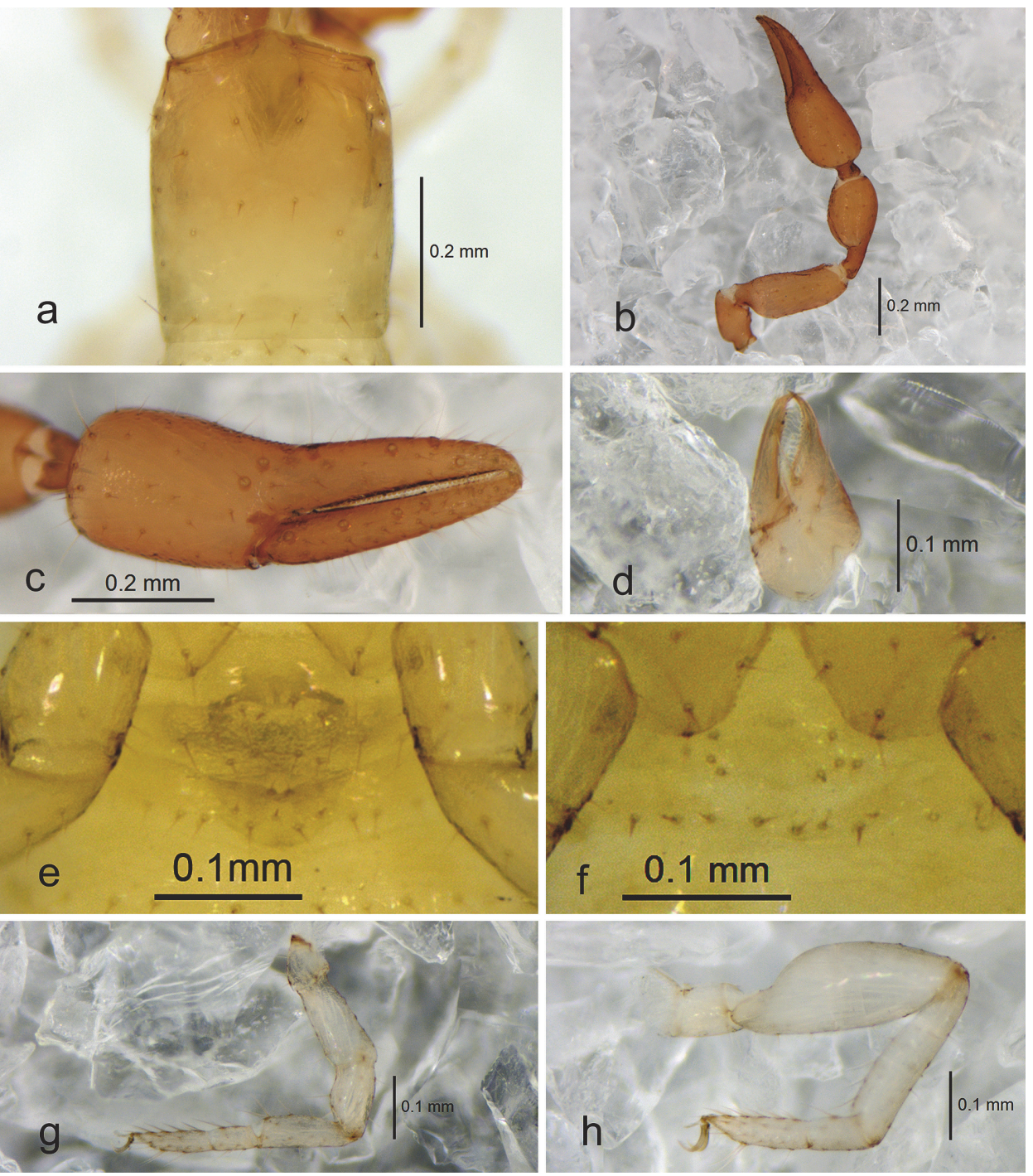

Fig. 6. Bisetocreagris parva sp. n., holotype male (Figs a-e, g, h), paratype female (Fig. f): $a=$ carapace, dorsal view, $\mathrm{b}=$ right pedipalp, dorsal view, $\mathrm{c}=$ right chela, lateral view, $\mathrm{d}=$ left chelicera, dorsal view, $\mathrm{e}=$ genital area of male, $\mathrm{f}=$ genital area of female; $\mathrm{g}=$ right leg $\mathrm{I}$, lateral view, $\mathrm{h}=$ right leg IV, lateral view 
length 0.16-0.17. Pedipalpal trochanter 0.19-0.21×0.11 (1.73-1.91), femur $0.35 \times 0.14(2.50)$, patella $0.33 \times 0.15-0.16(2.06-2.20)$, chela (with pedicel) $0.59-0.62 \times 0.17-0.19(3.26-3.47)$, chela (without pedicel) $0.54-0.58 \times 0.17-0.19$ (3.05-3.18), hand length (without pedicel) 0.23 , movable finger length $0.34-0.36(1.48-1.57 \times$ hand). Leg I: trochanter $0.08 \times 0.06(1.33)$, femur 0.14 $0.16 \times 0.07(2.00-2.29)$, patella $0.11-0.12 \times 0.06(1.83-2.00)$, tibia $0.15-0.16 \times 0.05(3.00-3.20)$, basitarsus $0.07-0.08 \times 0.04(1.75-2.00)$, telotarsus $0.11-0.12 \times 0.04(2.75-3.00)$. Leg IV: trochanter $0.12-0.13 \times 0.09(1.33-1.44)$, femur + patella $0.29-0.33 \times 0.13(2.23-2.54)$, tibia $0.26-0.27 \times 0.07$ (3.71-3.86), basitarsus $0.09 \times 0.05-0.06(1.50-1.86)$, telotarsus $0.15 \times 0.05(3.00)$.

Female - Body length 1.61-1.82. Carapace 0.42×0.35-0.36 (1.17-1.2). Chelicera: $0.25-$ $0.26 \times 0.13(1.92-2.00)$, movable finger length $0.18-0.19$. Pedipalpal trochanter $0.18-0.20 \times 0.12$ (1.50-1.67), femur $0.36-0.39 \times 0.15-0.16(2.40-2.44)$, patella $0.33-0.36 \times 0.16-0.17(2.06-2.12)$, chela (with pedicel) $0.64-0.68 \times 0.20-0.22(3.09-3.20)$, chela (without pedicel) $0.59-0.62 \times 0.20$ 0.22 (2.82-2.95), hand length (without pedicel) $0.28-0.30$, movable finger length $0.35-0.36$ (1.20-1.29×hand). Leg I: trochanter $0.08-0.09 \times 0.06(1.33-1.50)$, femur $0.16 \times 0.07(2.29)$, patella $0.12-0.13 \times 0.06-0.07(1.86-2.00)$, tibia $0.14-0.16 \times 0.05(2.80-3.20)$, basitarsus $0.07-0.08 \times 0.04$ (1.75-2.00), telotarsus $0.12-0.13 \times 0.03-0.04(3.25-4.00)$. Leg IV: trochanter $0.13 \times 0.10(1.30)$, femur + patella $0.24-0.29 \times 0.10-0.12(2.40-2.42)$, tibia $0.21-0.24 \times 0.06-0.07(3.43-3.50)$, basitarsus $0.08 \times 0.05(1.60)$, telotarsus $0.13-0.14 \times 0.04-0.05(2.80-3.25)$.

Distribution - China (Zhejiang).

Remarks - This new species has a small body and is mostly pale yellow, appearing to be immature. After careful examination, we found all specimens had 12 trichobothria on pedipalpal chela and the males had sclerotized genitalia. This species can be easily separated from the other three small species, B. philippinensis (Beier, 1931), B. nankingensis and B. thailandica, by the following characters: rallum with 7 blades (rallum with 8-9 blades in the other three species), apex of coxa with 3 setae (apex of coxa with 4 setae in B. philippinensis, 4-5 setae in B. nankingensis and B. thailandica), pedipalpal femur, patella and chela with granulations (femur, patella and chela smooth in B. nankingensis, patella and chela smooth in B. thailandica), sturdy pedipalpal femur (which in B. philippinensis and B. nankingensis is more slender, B. philippinensis pedipalpal femur 3.4-3.5 vs 2.5 times longer than broad in male, $B$. nankingensis pedipalpal femur 3.90 vs 2.40-2.44 times longer than broad in female), and its tiny size (length of pedipalpal femur at most $0.39 \mathrm{~mm} v s$ at least $0.46 \mathrm{~mm}$ in thailandica and philippinensis and $0.82 \mathrm{~mm}$ in nankingensis).

B. parva was collected in the litter and soil in a bamboo grove. The environment was somewhat dry, and the litter was a little thinner than in other habitats. It is possible that the small size of this species is caused by the habitat, but further study is required to prove this assumption.

Acknowledgements - We are grateful to Jie Yang and Zhizhong Gao for collecting the specimens. Prof. Victor Fet kindly helped reviewing the English of the manuscript. This work was supported by the National Natural Science Foundation of China (No. 31372154) 
and a Program of Ministry of Science and Technology of Republic of China (2015FY210300) to Feng Zhang.

\section{REFERENCES}

BeIer, M. (1931): Neue Pseudoscorpione der U. O. Neobisiinea. Mitteilung aus dem Zoologischen Museum in Berlin 17: 299-318.

Chamberlin, J. C. (1931): The arachnid order Chelonethida. Stanford University Publications. Biological Sciences 7(1): 1-284.

Ćurčıć, B. P. M. (1983): A revision of some Asian species of Microcreagris Balzan, 1892 (Neobisiidae, Pseudoscorpiones). Bulletin of the British Arachnological Society 6: 23-36.

Dashdamirov, S. \& Schawaller, W. (1992): Pseudoscorpions from Middle Asia, Part 1 (Arachnida: Pseudoscorpiones). Stuttgarter Beiträge zur Naturkunde (A) 474: 1-18.

Harvey, M. S. (1992): The phylogeny and classification of the Pseudoscorpionida (Chelicerata: Arachnida). Invertebrate Taxonomy 6: 1373-1435. https://doi.org/10.1071/IT9921373

Harvey, M. S. (1999): The Asian species of Microcreagris Balzan (Pseudoscorpiones: Neobisiidae) described by J.C. Chamberlin. Acta Arachnologica 48: 93-105. https://doi. org/10.2476/asjaa.48.93

Harvey, M. S. (2013): Pseudoscorpions of the World, version 3.0. Western Australian Museum, Perth. http://museum.wa.gov.au/catalogues-beta/pseudoscorpions. (Accessed 9 December 2015).

Judson, M. L. I. (1993): An abnormal, parasitized pseudoscorpion-holotype of Pedalocreagris tethys Ćurčić (=Bisetocreagris ussuriensis (Redikorzev), n. syn.) (Arachnida: Chelonethi: Neobisiidae). Journal of Natural History 27: 1207-1211. https://doi. org/10.1080/00222939300770701

Judson, M. L. I. (2007): A new and endangered species of the pseudoscorpion genus Lagynochthonius from a cave in Vietnam, with notes on chelal morphology and the composition of the Tyrannochthoniini (Arachnida, Chelonethi, Chthoniidae). Zootaxa 1627: 53-68.

Schawaller, W. (1985): Pseudoskorpione aus der Sowjetunion (Arachnida: Pseudoscorpiones). Stuttgarter Beiträge zur Naturkunde (A) 385: 1-12.

Zhaо, Y. W., Zhang, F., JiA, Y. \& Zhu, M. S. (2011): A checklist of pseudoscorpions from China (Arachnida: Pseudoscorpiones). Acta Arachnologica Sinica 20 (1): 30-41.

Received December 10, 2015, accepted June 4, 2016, published March 3, 2017 